\title{
Credibilidad percibida del periodismo a través de la Internet: una visión desde la psicología del consumidor*
}

\author{
Perceived Quality of Online Journalism: \\ a Vision From Consumer Psychology
}

\author{
Catalina Piñeros-Piza ${ }^{1}$ \\ Universidad del Rosario, Colombia \\ Liliana María Gutiérrez Coba ${ }^{2}$ \\ Universidad de la Sabana (Chía, Colombia) \\ Javier Andrés Gómez Díaz ${ }^{1}$ \\ Universidad del Rosario, Colombia \\ Andrés M. Pérez-Acosta ${ }^{1}$ \\ Universidad del Rosario, Colombia \\ Andrea Salgado Cardona ${ }^{2}$ \\ Universidad de la Sabana (Chía, Colombia) \\ María Lucía Mora² \\ Universidad de la Sabana (Chía, Colombia) \\ Nataly Grijalva² \\ Universidad de la Sabana (Chía, Colombia) \\ Juliana Estrada ${ }^{2}$ \\ Universidad de la Sabana (Chía, Colombia) \\ María José Ramírez ${ }^{2}$ \\ Universidad de la Sabana (Chía, Colombia) \\ Recibido: 27 de abril de 2011 \\ Revisado: 2 de mayo de 2011 \\ Aceptado: 30 de junio de 2011
}

\section{Resumen}

En el presente artículo se describen algunos criterios de credibilidad percibida que las personas usan cuando juzgan el periodismo en Internet. Estos criterios fueron comparados con los hallados en la literatura en contextos internacionales sobre credibilidad en el periodismo. Con una muestra de 166 participantes, quienes calificaron con una escala tipo Likert. Se exploró la credibilidad percibida que tienen los colombianos sobre el periodismo en Internet. Los resultados encontrados muestran que hay concordancia entre los criterios encontrados en la literatura y los usados por los lectores, no obstante, se halló una correlación negativa entre la dependencia al Internet (profesional/académica) y el nivel de credibilidad, al igual que entre las variaciones en el nivel de credibilidad con base en algunas variables socio-demográficas.

Palabras clave: credibilidad percibida del periodismo en internet, dependencia del Internet, consumo periodístico.

Artículo de investigación. Proyecto de investigación 'Calidad percibida de los medios periodísticos en Internet por parte del consumidor de noticias', financiado por la Universidad de la Sabana (Colombia).

** Correspondencia: Liliana María Gutiérrez Coba, Programa de Comunicación Social y Periodismo, Universidad de la Sabana. Dirección postal: Campus Universitario de Puente del Común, Chía (Cundinamarca), Colombia. Correo electrónico: liliana.gutierrez1@unisabana.edu.co. 


\section{Abstract}

This article describes some perceived credibility criteria that people use when judging Internet journalism. These criteria were compared with those found in the literature on journalism credibility in international contexts. With a sample of 166 participants who rated with a Likert scale, were explored the perceived credibility that has Colombian people about Internet journalism. Results show that there is agreement between the criteria found in the research literature and those used by online readers, however, were found a negative correlation between Internet dependence (professional/scholar) and the level of credibility, as well as between changes in the level of credibility and some socio-demographic variables.

Keywords: perceived internet journalism credibility, Internet dependence, journalism consumption.

\section{Introducción}

La Internet ha permitido que cada persona pueda acceder a cualquier información y es deber de cada persona juzgar qué información considera verdadera y apta para su consumo. Sin embargo, ¿cuáles son los factores que hacen que las personas crean o no en determinadas fuentes de información, o en determinado tipo de información? El presente estudio explora estos factores, partiendo de lo hallado en la literatura psicológica sobre credibilidad y autoridad percibida, haciendo un recorrido por las generalidades de la calidad del periodismo en Colombia.

Desde que existen los medios de comunicación masivos en Colombia, se ha manifestado una afiliación política de estos (Santos Calderón, 1989), aunque los medios tiendan a cambiar esta percepción, esta situación le deja dos caminos al consumidor de información: (1) optar por creer en lo que estos medios dicen, sabiendo que tienen un sesgo informativo o, por el contrario, (2) tomar una postura crítica respecto a los medios informativos. Debido a que pocas personas invierten su tiempo en lo último y suelen asumir como cierto lo que los medios informativos publican, se termina creyendo lo que dice el medio más tradicional o el que más se consume.

El concepto de credibilidad es de orden multidimensional, lo que hace que sea difícil de definir, tanto por la psicología social y del consumidor como por las ciencias de la comunicación. La primera lo ha asociado con el proceso persuasi- vo bajo la tesis de que la credibilidad es uno de los factores que influyen en este proceso (Myers, 2005; Rieh \& Danielson, 2007; Stavrositu \& Sundar, 2008), mientras que la segunda ha investigado ampliamente los factores asociados con la credibilidad de los medios informativos (Greer, 2003; Hovland, Janis \& Kelley, 1953; Sternthal, Dholakia \& Leavitt, 1978; entre muchos otros).

La persuasión ha sido descrita como el proceso por el cual un emisor intenta cambiar las actitudes o comportamientos específicos del receptor y se da mediante una serie de etapas en la que los estímulos de la comunicación son filtrados a través de la disposición del receptor y generan respuestas internas pero manifestadas en respuestas observables (Moya, 1999). En los medios masivos este concepto aplicaría, por ejemplo, en el intento de estos por persuadir a su público para que asuman ciertas actitudes respecto a diversos temas.

Las actitudes además reflejan lo que nos suele (dis)gustar y tener una actitud favorable frente a un producto o servicio suele ser el prerrequisito para tener una intención de compra o consumo. Sin embargo, siendo la prensa en línea un producto que carece de precio, es plausible afirmar que la actitud positiva hacia ésta, como producto, conllevará a su consumo, lo que a su vez aportará a su credibilidad en el consumidor de noticias.

Consecuentemente con la persuasión y las actitudes, la influencia social se sirve de este proceso persuasivo. Según Cialdini y Mortensen (2007), la influencia social define el proceso por el cual se 
trata de cambiar el comportamiento de las personas para que se ajuste al de otras, y que los medios suelen usar para crear determinadas imágenes de realidad. Este proceso se puede dar de tres maneras: obediencia, conformidad y sumisión. De estas tres formas de influencia, la conformidad es un indicador de lo que sucede en la mente de los consumidores de información, pues nos dice que, cuando las situaciones son ambiguas, las personas se guían por el comportamiento de otros para tomar decisiones sobre sus acciones (Cialdini \& Mortensen, 2007).

Por otro lado, el proceso de conformidad se puede llegar a dar para obtener la aprobación de otros, siguiendo una similitud con la espiral del silencio, ya que dicha aprobación no refleja necesariamente la opinión propia (Cialdini \& Mortensen, 2007). Esto significa que las personas, en relación con la credibilidad de los medios en Internet, elijen como más creíble aquellos medios que son reconocidos por otros como creíbles, es decir, aquellos que por tradición son consumidos. Adicionalmente, la lectura de información periodística a través de las redes sociales refleja, al menos, parcialmente la búsqueda de aceptación por parte de un grupo de referencia.

Autores como Pornpitakpan (2004), quien ha revisado el tema de la persuasión y particularmente la credibilidad de la fuente, ha identificado como factores determinantes de la credibilidad a la experticia y a la confiabilidad atribuible al medio. Estos dos factores se han revisado ampliamente en la literatura y han sido tomados como indicadores de credibilidad de la fuente (Flanagin y Metzger, 2007; Nozato, 2002; Swan, 2004).

Pornpitakpan (2004) define como experticia la capacidad del hablante de hacer ciertas conclusiones acertadas y la confiabilidad como el grado en que la audiencia percibe las conclusiones como válidas.

Así mismo, Hovland, Janis y Kelley (1953) proponen la teoría de la credibilidad de la fuente, en ella exponen que la gente será persuadida más fácilmente cuando la fuente se presenta como creíble. Esta teoría presenta tres modelos: el factorial, el funcional y el constructivista. El modelo factorial ayuda a determinar en qué medida se califica la fuente como creíble, el modelo funcional ve la credibilidad como el grado en que la fuente satisface las necesidades individuales del receptor y el modelo constructivista analiza lo que el receptor hace con la propuesta de la fuente. En esta medida la credibilidad que perciben los receptores de la información difundida por Internet se presenta en tres componentes: atribución de credibilidad, la satisfacción de necesidades y el uso de la información.

Pornpitakpian (2004) resume las variables de credibilidad de acuerdo con (1) la fuente, (2) el mensaje, (3) el canal, (4) el receptor, y (5) el destino. La Tabla 1 muestra cada una de las variables según su pertenencia. Estas variables sintetizan eficazmente los factores que afectan la credibilidad de la información y son parte del instrumento, excepto por la variable de destino, ya que su tratamiento requería de un estudio con mayores niveles de control.

Para el presente estudio se tomaron en cuenta la fuente y el canal de comunicación en función de la credibilidad percibida de la información en línea.

De acuerdo con los elementos de la comunicación la credibilidad ha sido estudiada desde el rol que desempeña la fuente en la persuasión. Tormala, Briñol y Petty (2007) en dos experimentos encontraron el efecto de la credibilidad de la fuente en los pensamientos de favorabilidad y los pensamientos de confianza de un mensaje cuando se conoce previamente o posteriormente la información de la fuente.

De otro lado, una de las características de la fuente es la autoridad que posee o con la cual es percibida por parte de los receptores. Galegher, Sproull y Kiesler (1988) proponen que la autoridad en los medios electrónicos es inherentemente interactiva por la posibilidad de consultar directamente a sus autores. 
Tabla 1.

Variables de credibilidad según Pornpitakpian (2004)

\begin{tabular}{|c|c|c|c|c|}
\hline $\begin{array}{l}\text { Variables } \\
\text { de la fuente }\end{array}$ & $\begin{array}{l}\text { Variables } \\
\text { del mensaje }\end{array}$ & Variables del canal & $\begin{array}{l}\text { Variables } \\
\text { del receptor }\end{array}$ & $\begin{array}{l}\text { Variables } \\
\text { del destino }\end{array}$ \\
\hline Atractividad física & $\begin{array}{l}\text { momento de } \\
\text { identificación de la } \\
\text { fuente }\end{array}$ & $\begin{array}{l}\text { Modalidad del } \\
\text { medio }\end{array}$ & Disposición inicial & $\begin{array}{l}\text { Tiempo pasado } \\
\text { después de la } \\
\text { exposición }\end{array}$ \\
\hline $\begin{array}{l}\text { Semejanza entre } \\
\text { fuente y receptor }\end{array}$ & $\begin{array}{l}\text { Presencia de } \\
\text { evidencia }\end{array}$ & $\begin{array}{l}\text { Experiencia directa } \\
\text { con los objetos }\end{array}$ & $\begin{array}{l}\text { Participación en los } \\
\text { temas }\end{array}$ & $\begin{array}{l}\text { Apelación contra } \\
\text { persuasiva }\end{array}$ \\
\hline \multirow[t]{10}{*}{ Género } & $\begin{array}{l}\text { Presencia de } \\
\text { argumentos de } \\
\text { soporte }\end{array}$ & $\begin{array}{l}\text { Compresión de } \\
\text { tiempo de } \\
\text { exposición }\end{array}$ & $\begin{array}{l}\text { Comportamiento de } \\
\text { las personas }\end{array}$ & Tipo de producto \\
\hline & $\begin{array}{l}\text { Calidad de los } \\
\text { argumentos }\end{array}$ & Presión del tiempo & Autoritarismo & \\
\hline & $\begin{array}{l}\text { Discrepancia del } \\
\text { mensaje }\end{array}$ & & Dogmatismo & \\
\hline & $\begin{array}{l}\text { Participación de } \\
\text { emisión }\end{array}$ & & $\begin{array}{l}\text { Represión y } \\
\text { sensibilización }\end{array}$ & \\
\hline & $\begin{array}{l}\text { Amenaza del } \\
\text { Mensaje }\end{array}$ & & $\begin{array}{l}\text { Acceso a } \\
\text { información } \\
\text { relevante }\end{array}$ & \\
\hline & Estilo del mensaje & & Auto-monitoreo & \\
\hline & $\begin{array}{l}\text { Intensidad del } \\
\text { lenguaje }\end{array}$ & & $\begin{array}{l}\text { Orientación de } \\
\text { certeza }\end{array}$ & \\
\hline & $\begin{array}{l}\text { Cantidad del } \\
\text { mensaje }\end{array}$ & & $\begin{array}{l}\text { Diferenciación de } \\
\text { estímulos }\end{array}$ & \\
\hline & $\begin{array}{l}\text { Inclusión de la } \\
\text { refutación }\end{array}$ & & Locus de control & \\
\hline & $\begin{array}{l}\text { Congruencia del } \\
\text { mensaje con los } \\
\text { intereses de la } \\
\text { fuente }\end{array}$ & & $\begin{array}{l}\text { Necesidad de } \\
\text { cognición }\end{array}$ & \\
\hline
\end{tabular}

Igualmente, se ha definido la autoridad en términos de credenciales profesionales o profesionalismo, ya que los argumentos dados por personas expertas suelen ser percibidos como relevantes sobre el tema en particular e incluso suficientes con base en las necesidades del público (Galegher, Sproull y Kiesler, 1988). A modo de complemento, Robinson (2008) define la autoridad como "el poder implicado e inferido de alguien para transmitir información o, al menos, como es percibida por los consumidores de noticias" (p. 3).

Por otro lado, para O’Keefe (2002), la definición de credibilidad, también se asocia con el autor de la comunicación, pues la asume como el juicio hecho por el receptor concerniente al nivel de verdad de un comunicador (o mensaje). Este autor propone dos características que se estudian 
cuando se quiere determinar la credibilidad de la fuente: (1) la experticia y (2) la confiabilidad del comunicador. Para determinar la credibilidad de la fuente con base en estos dos factores se tiene en cuenta también: la educación, la ocupación y la experiencia del emisor; la fluidez en la transmisión del mensaje; la citación de fuentes y la posición defendida por el emisor (O’Keefe, 2002).

Complementariamente, en el meta-análisis realizado por Wilson y Sherrell (1993, citados en Wathen y Burkell, 2002), se pudo establecer que las investigaciones sobre credibilidad han sido dirigidas con base en los efectos de la fuente, del mensaje o del medio, por lo que una definición más de credibilidad sería

una fuente de comunicación posee credibilidad si sus declaraciones son consideradas confiables y validas...y por lo tanto, respetable de consideración seria. Un miembro de una audiencia objetivo puede aceptar la influencia de la fuente de comunicación porque su comportamiento es congruente con sus propios sistemas de valores (p. 136).

En el estudio realizado por Galegher, Sproull y Kiesler (1988), sobre la legitimidad, la autoridad y la comunidad en grupos de ayuda virtuales, se identificó que, aunque un argumento contenga para algunos receptores autoridad, ésta puede no ser vista por otros receptores.

El contenido del mensaje es otro elemento que afecta la credibilidad, particularmente si se asocia con razones y argumentos lógicos-válidos o se apele a las emociones y consecuencias de la aceptación/rechazo del mensaje o la cantidad de recursos (audio, video, etc.) que se use. Esto a su vez depende de las características de los receptores del mensaje, ya que algunas personas son más susceptibles a creer más en argumentos lógicos válidos, y otras son más susceptibles a creer cuando se hace uso de mensajes cargados de emociones. Del mismo modo, otros elementos del contenido del mensaje, como la refutación a través de contraargumentos, así como la ignorancia de los argumentos son tomados en cuenta cuando se evalúa la credibilidad.
De acuerdo con el mensaje como elemento de la persuasión y de la credibilidad, Kiousis (2006) realizó una investigación en la que se preguntó por el uso de contenido multimedia y su influencia en la credibilidad de la fuente y del mensaje. Los resultados del estudio mostraron que no hay efectos directos en la evaluación de la credibilidad en una noticia en Internet, ya sea respecto a credibilidad de la fuente o del mensaje, sin embargo, sí se halló mayor credibilidad comparado con contenidos sin multimedia. Igualmente, se encontró un efecto positivo en la credibilidad de la fuente cuando se hizo uso del contenido multimedia respecto a la credibilidad del mensaje.

Finalmente, el último elemento de la persuasión que está ligado a la credibilidad es el receptor, dado que todo mensaje lleva una vía de emisiónmedio-recepción. Según Pardo (1989), todo mensaje emitido se espera ser recibido por una comunidad receptora ideal, esto quiere decir que pueda entender el mensaje y este sea aceptado o, en otras palabras, que el receptor sea persuadido sin mayor complicación, sin embargo, no sucede de esta manera ya que el receptor es una persona crítica con capacidad de evaluación y que puede identificar diferentes características del mensaje y de la fuente que le permiten, a su vez, evaluar la credibilidad de la misma. En últimas, quien determina la credibilidad de una fuente o de un mensaje es el receptor del mensaje: el consumidor de noticias.

Respecto al receptor hay que añadir que en el ámbito del comportamiento del consumidor ha trabajado acerca de las creencias de las personas como un factor que también contribuye a la credibilidad que se le otorga a un medio, producto o persona (Blackwell, Miniard y Engel, 2002). El receptor, como agente a ser persuadido, es en última instancia quien determina, como consumidor de noticias y con base en sus creencias, la credibilidad de una fuente o de un mensaje. Las creencias, al ser juicios subjetivos respecto a la relación entre dos o más atributos de productos/ servicios, hacen parte de la definición de una actitud (des)favorable hacia estos, de tal forma que, si tales atributos se muestran con credibilidad, en mayor o menor medida, ésta será adjudi- 
cada al producto o al servicio (Blackwell, Miniard y Engel, 2002).

En concordancia con el elemento receptor, Fogg (2003) postuló, en su teoría de la prominenciainterpretación, que dos cosas pasan cuando las personas juzga la credibilidad de la información en línea: (1) los usuarios notan algo (prominencia) y (2) los usuarios hacen un juicio sobre eso que notan (interpretación). La prominencia es la probabilidad de que un elemento del sitio de Internet o website sea notado o percibido; si no lo es, no afectará el juicio de credibilidad. Este autor propone cinco factores de prominencia: (1) participación; (2) tema; (3) tarea del usuario; (4) experiencia del usuario; (5) diferencias individuales (necesidad de cognición, estilo de aprendizaje, nivel de literatura, entre muchas otras). Para este autor, la interpretación es el momento en que el usuario evalúa los elementos notados, y además propone tres factores que la afectan: (1) asunciones del usuario (prejuicios, cultura, experiencias pasadas o heurísticos); (2) habilidades/ conocimientos; y (3) el contexto del sujeto, las normas de la sociedad en que vive y sus expectativas. Dicho autor explica que este proceso se repite una y otra vez, y que esta teoría puede explicar resultados de investigaciones pasadas acerca de la credibilidad y también predecir los resultados de futuras investigaciones.

Siguiendo esta línea, la credibilidad estaría ligada a la percepción que se tenga de cada uno de los elementos de la persuasión y a las actitudes con respecto a los productos o servicios.

Pérez (1996) muestra un modelo en el que define qué es consumir medios de comunicación, para ello da unos puntos claves que describen el proceso de consumo: (1) disponer de un espaciotiempo de consumo; (2) asumir un punto de vista sobre el entorno; (3) establecer una relación con el interlocutor; (4) integrarse en una comunidad (a través de los medios); (5) conocer determinados temas (ej.: agenda pública); (6) seguir un curso de razonamiento (qué y cómo pensar); (7) aceptar una estética; (8) tener una postura ante unos valores; (9) plantearse unas propuestas de acción; y (10) participar en el proceso de cons- trucción de una cultura. Según estos puntos, el consumo de medios de comunicación hace parte de la formación de identidad, es por ello que consumirlos críticamente es tan importante, pues, si aceptamos como verdadero todo aquello que dicen en los medios, estaríamos dejando que modelen nuestras vidas.

Cassidy (2007), por su parte, estudió la credibilidad en relación con la dependencia del Internet y la confianza en este medio. La población evaluada fueron periodistas de Internet y de prensa escrita. El autor concluyó que aquellas personas que por su trabajo y en general sus condiciones de vida consultan más la Internet tendrán mayor credibilidad en la información que se obtenga de esta fuente. Sin embargo, el hecho de que la población incluida en el estudio sea periodistas, se constituye en un sesgo por su conocimiento de criterios de calidad, por lo que en el presente estudio se obviaron las contribuciones de periodistas y de estudiantes de periodismo.

De acuerdo con el canal, como elemento de la persuasión y de la credibilidad, Kiousis (2006) realizó una investigación en la que se preguntó por el uso de contenido multimedia y su influencia en la credibilidad de la fuente y del mensaje. Sus resultados muestran que no hay efectos directos en la evaluación de la credibilidad en una noticia en Internet, ya sea respecto a credibilidad de la fuente o del mensaje; sin embargo, se halló mayor credibilidad comparado con contenidos sin multimedia.

Busy (2003) además encontró que el Internet, como canal de comunicación, está relacionado con la edad del participante y la simultaneidad de uso, encontrando que los jóvenes tienen mayor credibilidad en los medios televisivos y los adultos en la Internet, incluso cuando fueron expuestos simultáneamente a la televisión y la Internet; sin embargo, en general, los jóvenes tienen índices más altos de credibilidad que los adultos.

Pasando a la teoría de la comunicación se encuentran dos fenómenos importantes que describen la manera en que se escogen las notas periodísticas que se publicarán y la forma en que los consumi- 
dores de noticias adoptan la información presentada en los medios masivos. Estos fenómenos son la fijación de agenda (en inglés 'setting agenda', McCombs y Shaw, 1972) y la espiral del silencio (Noelle-Neumann, 1974) que se constituyen en elementos que ayudan a controlar la información. Estas perspectivas brindan un indicio de qué es lo que ocurre antes de que las noticias lleguen a nuestras manos.

La fijación de agenda (McCombs y Shaw, 1972) describe cómo las noticias son jerarquizadas en orden de importancia por parte del editor o jefe del medio y es quien elige las noticias que van a ser publicadas y ofrecidas al consumidor de información, de tal manera que se descartan u ocultan algunas noticias, dependiendo de los intereses que el medio periodístico tenga o de la pertinencia de la información.

La espiral del silencio (Noelle-Neumann, 1974) trata sobre la perpetuación del mismo en las personas, en forma de espiral, por temor a ser rechazados por los demás; en este sentido, a medida que la opinión pública tenga poder, las personas sentirán mayor temor de mostrar sus opiniones propias (Monzón, 1996).

Estos fenómenos de la escogencia y difusión de noticias muestran en alguna medida el poder simbólico de los medios que, según Thomson (1998) permite designar "la capacidad de intervenir en el transcurso de los acontecimientos, para influir en las acciones de los otros y crear acontecimientos..., a través de los medios de producción y transmisión de las formas simbólicas" (p. 34).

A continuación se relacionan algunos otros estudios que dan un esbozo sobre la manipulación de la información y la credibilidad de ésta.

Gaziano y Mcgrath (1986) encontraron en su estudio que las personas solían elegir como medio de mayor credibilidad a la televisión, ya que este medio les puede dar la posibilidad de ver imágenes, y las personas creen en lo que ven. De aquí se podría asumir el uso de multimedia en Internet como indicador de credibilidad en este medio.
La sinceridad percibida de una fuente depende también de la carencia de un interés particular con la transmisión de información, es decir, la ausencia de interés persuasivo. Del mismo modo, el atractivo y el poder de la fuente son características que logran mayor o menor persuasión en el receptor (Moya, 1999). Tales factores podrían influenciar, a su vez, la credibilidad con que es percibida la fuente.

Al estar la credibilidad relacionada con el proceso de persuasión, el modelo de probabilidad de elaboración (Petty y Cacioppo, 1986) demuestra el contraste entre las actitudes formadas por menor demanda cognitiva y formadas a través de procesos como el condicionamiento clásico, los heurísticos y las inferencias, también llamadas rutas periféricas que son menos persistentes en el comportamiento, a diferencia de la ruta central, donde los argumentos, en este caso, el contenido de un mensaje podría ser la fuente de credibilidad y no el reconocimiento público del autor o del medio.

Wathen y Burkell (2002) aplicaron los criterios definidos por Wilson y Sherrell (1993, citados por ellos mismos) a la información en línea e incluyendo además factores cognitivos o técnicos. Dentro de los factores cognitivos están: la competencia, la fiabilidad, la relevancia y la autoridad cognitiva; y dentro de los técnicos: la novedad, la accesibilidad, la flexibilidad o las claves. Estos factores dan como resultado la calidad institucional percibida. Estos autores encontraron que algunas de las herramientas utilizadas por los consumidores para definir la credibilidad de un sitio web fueron la dirección del mismo (URL), la referencia de un colega, de un conocido y de un experto, concluyendo que hay siete criterios de credibilidad en la web: 1) fuente, 2) contenido, 3) formato, 4) presentación, 5) precisión, 6) velocidad de carga y 7) actualización.

Fogg (2003), sin embargo, propuso cuatro tipos de credibilidad: (1) supuesta (dada por asunciones generales sobre algo o alguien), (2) por fama (dada por la impresión de terceras personas), (3) a primera vista (dada por inspecciones simples que no van más allá de la portada) y (4) por expe- 
riencia (como su nombre lo indica está dada por la primera experiencia con el objeto o persona).

Rieh y Danielson (2007) proponen, por su parte, que al evaluar la credibilidad es necesario hacer una distinción entre los juicios predictivos antes de tener contacto con el objeto de evaluación y los juicios valorativos cuando ya se ha tenido contacto con el mismo. Debido a que antes de leer el documento o noticia en Internet se deducen, primero, algunas impresiones producto del título y los aspectos físicos de la página web, esto brinda indicios acerca de la credibilidad de la información en la web y, por otro lado, el texto da otros factores de credibilidad de la información en la web.

En la literatura encontrada, que se describe a continuación acerca de la credibilidad en Internet, se ha evidenciado que gran parte de la credibilidad corresponde al juicio formado después de tener un contacto con el medio informativo, así lo demuestran las siguientes investigaciones, en las cuales puede explicarse este modo de evaluación debido a que en la mayor parte el mensaje en sí mismo es evaluado.

En un estudio realizado por Lui (1989) se analizó la credibilidad del comunicador, empleando tres tipos de fuentes; (1) conocida, (2) experta y (3) neutral; la credibilidad se midió mediante un cuestionario de cuatro ítems que fue resuelto por tres grupos de individuos que escucharon las grabaciones de los tres tipos de fuentes. En los resultados se halló que entre las fuentes experta y neutral no había diferencias significativas, por lo que se deduce que la conocida se asocia a la credibilidad.

Nozato (2002) realizó un estudio en el cual evaluó cómo los estudiantes universitarios juzgan la credibilidad de la prensa en línea. Para esto definió 14 factores para evaluar la credibilidad: experticia, objetividad, dinamismo, equidad, ausencia de sesgo, integridad, exactitud, confiabilidad, confiabilidad de la noticia, reputación de la fuente, fiabilidad de la fuente, interactividad y proceso editorial. Los estudiantes debían responder si esos factores se presentaban como ca- racterísticas de los periódicos en línea, mediante una escala Likert de cinco puntos que iba desde muy de acuerdo hasta muy en desacuerdo. Se tomaron en cuenta como variables independientes: (1) Experiencia individual con el Internet, (2) Uso individual de periódicos en línea, (3) la frecuencia de uso de periódicos en línea y (4) La familiaridad del periódico en físico. En este estudio se encontró que los estudiantes universitarios tenían alta credibilidad en los medios noticiosos en Internet, aunque estos resultados no difieren en gran medida de los medios tradicionales.

Sundar (1998) realizó un estudio en el que quería responder a la pregunta: ¿son las fuentes citadas en noticias en Internet psicológicamente significativas así como lo son en la prensa? Este estudio se realizó mediante un diseño pre-experimental (no contaba con grupo control) con dos variables: presencia y ausencia de fuentes citadas. El instrumento de evaluación fue un cuestionario que incluyó tanto la credibilidad como la calidad y la representatividad mediante adjetivos calificativos en una escala Likert. La variable de credibilidad se midió bajo los criterios de exactitud, credibilidad, sesgo, justicia, objetividad y sensacionalismo. El autor encontró diferencias significativas en la credibilidad y la calidad de textos con presencia de citas y ausencia de éstas.

Kiousis (2006) estudió la influencia de la modalidad web en las percepciones de las personas sobre la credibilidad de la fuente y del mensaje en historia en Internet. El estudio realizado fue mediante tres condiciones de modalidades de web: (1) sólo texto; (2) texto y fotos; y (3) texto, fotos y video. Después de leer la historia, los participantes debían responder un cuestionario que se basó en siete dimensiones de credibilidad: especificidad, exactitud, equidad, objetividad, sesgo y sensacionalismo, mediante una escala tipo Likert de siete puntos. Aunque no se hallaron diferencias significativas con base en la credibilidad de fuente o del mensaje en presencia de mensajes multimedia, sí se halló mayor credibilidad de la fuente cuando las personas usan multimedia constantemente; sin embargo, esto no influyó en la credibilidad del mensaje. 
Stavrositu y Sundar (2008) investigaron la relación entre los propósitos de uso del Internet y la credibilidad de la información periodística en este medio; para ello realizaron una encuesta por correo electrónico a estudiantes universitarios. Para medir la credibilidad utilizaron dos preguntas basadas en un concepto unidimensional de credibilidad. Las preguntas iban dirigidas a la fiabilidad del Internet y la fiabilidad del medio informativo on-line. Estos autores encontraron que la credibilidad del Internet es predicha por el uso de Internet y de la información periodística, y que el uso del Internet para informarse es predictor de credibilidad general del mismo aunque no supone el remplazo del consumo de información por medios tradicionales. También encontraron diferencias en cuando al propósito del consumo del medio, ya que en el caso del Internet es mayor la credibilidad cuando el propósito es informarse que entretenerse.

Teniendo en cuenta lo anteriormente expuesto, este estudio pretende describir los factores que intervienen en el juicio de la credibilidad percibida de los colombianos que se informan a través de la Internet.

\section{Método}

\section{Tipo de estudio}

Es un estudio no experimental descriptivo correlacional en el que se pretende observar la relación entre la credibilidad percibida respecto a variables como la fuente, el mensaje y el receptor.

\section{Participantes}

Se contó con la participación de 181 personas que voluntariamente respondieron al envío masivo de correo, invitando a hacer parte de esta investigación, por lo que resulta ser una muestra no probabilística. De esta muestra fueron excluidos los datos de 15 participantes por su condición de ser profesionales o estudiantes de carreras como comunicación social, periodismo y de psicología del consumidor específicamente, por su posible conocimiento previo acerca de la credibilidad y su me- dición, lo que podría generar sesgos al momento de contestar la encuesta. Igualmente, se excluyeron los participantes que reportaron tener menos de 18 años al momento de contestar la encuesta, por cuestiones éticas. El total de datos analizados fue de 166 personas ( 90 hombres y 76 mujeres). El $53 \%$ de ellos reportó tener estudios de postgrado, el $38.8 \%$ de pregrado y solo un $8.2 \%$ con estudios de secundaria. La media de edad fue de 36 años. Se obtuvo además una media de dependencia laboral o profesional del internet igual a 4.72 en una escala de 1 a 6 . Los estratos socioeconómicos predominantes fueron 3 y 4 .

\section{Instrumento}

Se utilizó una escala de calificación tipo Likert, que cuenta con 18 ítems, con un escalamiento de 1 a 6 que va desde: totalmente en desacuerdo $=1$, hasta totalmente de acuerdo $=6$, para conocer la credibilidad percibida de los consumidores de noticias por Internet, por ende, tiene un puntaje máximo de 108 y mínimo de 18. El índice de fiabilidad de la escala, según el Alpha de Cronbach, es de 0.76 .

La definición de credibilidad percibida acordada para este estudio es la confianza en el rigor, la verdad y la precisión de la información que publica un medio (Flanagin y Metzger, 2000; Johnson y Kaye, 2000; Nozato, 2002; Schweiger, 2000).

\section{Procedimiento}

Luego de una validación por jueces y la administración de una prueba piloto con estudiantes de periodismo, se descartaron tres ítems de los 21 ítems inicialmente propuestos para analizar la credibilidad percibida de la información periodística en internet. Para el envío de la encuesta se contrató un servicio de envío masivo de correo electrónico a un total de 115.251 usuarios registrados en Colombia. Se promovió la respuesta de la encuesta por un periodo de seis meses y, una vez obtenidas las respuestas de la muestra, se usaron los estadísticos correspondientes para el análisis de los resultados. 


\section{Implicaciones éticas}

De acuerdo con el artículo 15 de la Constitución de la República de Colombia, donde se habla del derecho a la intimidad de las personas y del respeto a la información de las personas, no solicitó información personal que permitiera la identificación del participante. Del mismo modo, los principios 6, 7 y 9 de la Ley 1090 del 2006, que regula la profesión de la psicología en Colombia, donde se habla sobre la confidencialidad y el bienestar del usuario, los participantes aceptaron contestar la encuesta antes de iniciarla y mediante un consentimiento informado se les informó sobre los objetivos del estudio y la confidencialidad de los datos que en ella se consignaron.

\section{Resultados}

Se encontró que los medios informativos online que más consultan los usuarios de la Internet suelen ser medios periodísticos con amplia tradición en prensa, en especial, seguidos por los de radio y televisión respectivamente.

También se comparó la credibilidad de los medios masivos de comunicación tradicionales y el Internet. Se encontró que la prensa es el medio con mayor credibilidad percibida, seguido por la Internet (prensa: media $=4.51 ; \mathrm{SD}=1.07$; Internet: prensa: media $=4.24 ; \mathrm{SD}=0.96), \quad[\mathrm{F}=(181,5)=53.88$; $p=0.00]$. No obstante, el $48,9 \%$ de los participantes tiende a otorgarle credibilidad a más de un medio informativo a la vez. Según el rango de edad, los participantes de 18 a 27 años le otorgan mayor credibilidad a la radio (media $=5.00$; $S D=0.96), \quad[F=(171,2)=7.61 ; p=0.00]$. Para los demás rangos de edad no se hallaron diferencias significativas en la credibilidad hacia otros medios [prensa: $\mathrm{F}=(171,2)=0.66 ; p=0.52$; televisión: $\mathrm{F}=(171,2)=1.04 ; p=0.36$; Internet: $\mathrm{F}=(171,2)=0.28$; $p=0.75]$.
Los participantes, en promedio, reportaron una notable dependencia del Internet (media=4.27; $S D=1.51$ ), y suelen basar su forma de juzgar la credibilidad de los medios informativos que consultan en las experiencias que han tenido previamente (moda=47.51), así como en las propias percepciones y opiniones del medio (moda=45.30). La primera impresión que se tuvo del medio o el concepto que otras personas tienen sobre el medio son los criterios menos frecuentes para juzgar dicha credibilidad (modas=4.97 y 2.21, respectivamente).

A continuación se reportan los resultados acerca de los criterios con los cuales calificaron los participantes la credibilidad percibida de la información periodística por Internet: el autor, el medio y el mensaje.

Con respecto al autor, se tuvo en cuenta el reconocimiento del mismo, su competencia periodística, su experticia, la confianza y la fiabilidad que generan en su público lector (consumidor), así como el sesgo (o la ausencia de este) para reportar sus notas periodísticas. Los criterios que más valoraron de los autores de noticias fueron su fiabilidad (media=16.92; $S D=1.55$ ) y su experticia (media=14.77; SD=2.62), no obstante, los demás criterios obtuvieron medias superiores a 8.5.

Con respecto al medio y al mensaje, los participantes reportaron como importante la confiabilidad de lo que se publica (media=8.50; $S D=1.50$ ), al contario de la importancia de la publicidad que acompaña las notas periodísticas (media=2.69; $\mathrm{SD}=1.54)$.

A su vez, se encontraron correlaciones significativas entre los criterios de credibilidad percibida de los autores y entre los criterios de la credibilidad percibida de la información periodística en Internet, las cuales se pueden observar en las tablas 2 y 3. 
Tabla 2.

Correlaciones entre los criterios de credibilidad percibida de los autores del periodismo en Internet

\begin{tabular}{|c|c|c|c|c|c|}
\hline $\begin{array}{l}\text { Criterios de } \\
\text { credibilidad }\end{array}$ & $\begin{array}{l}\text { Formación } \\
\text { profesional }\end{array}$ & Confianza & Experticia & Fiabilidad & Reputación \\
\hline $\begin{array}{l}\text { Formación } \\
\text { profesional }\end{array}$ & - & 0,11 & $0,39^{* *}$ & 0,13 & $0,16^{*}$ \\
\hline Confianza & 0,11 & - & 0,13 & $0,42^{* *}$ & 0,12 \\
\hline Experticia & $0,39^{* *}$ & 0,13 & - & $0,32^{* *}$ & $0,30^{* *}$ \\
\hline Fiabilidad & 0,13 & $0,42^{* *}$ & $0,32^{* *}$ & - & 0,02 \\
\hline Reputación & $0,16^{*}$ & 0,12 & $0,30^{* *}$ & 0,02 & - \\
\hline
\end{tabular}

Tabla 3.

Correlaciones entre los criterios de la credibilidad percibida de la información periodística en Internet

\begin{tabular}{lccc}
\hline & $\begin{array}{c}\text { Medios } \\
\text { informativos } \\
\text { por Internet }\end{array}$ & $\begin{array}{c}\text { Contenido } \\
\text { que se } \\
\text { publica }\end{array}$ & $\begin{array}{c}\text { Aporte del } \\
\text { autor al medio } \\
\text { informativo }\end{array}$ \\
$\begin{array}{l}\text { Medios } \\
\text { informativos } \\
\text { por Internet } \\
\begin{array}{l}\text { Contenido } \\
\text { que se } \\
\text { publica }\end{array}\end{array}$ & - & $0,29^{* *}$ & $0,32^{* *}$ \\
$\begin{array}{l}\text { Aporte del } \\
\text { autor al } \\
\text { medio } \\
\text { informativo }\end{array}$ & $0,32^{* *}$ & 0,07 & 0,07 \\
$* * *$ \\
\hline
\end{tabular}

Los consumidores de noticias vía Internet, participantes del estudio, percibieron que la formación profesional está más relacionada con la experticia (Pearson $=0.39 ; p=0.00$ ) que con la reputación del periodista (Pearson $=0.16 ; p=0.03$ ); mientras que la experticia está relacionada tanto con la fiabilidad (Pearson=0.32; $p=0.00$ ) como con su reputación (Pearson=0.30; $p=0.00$ ). Coherentemente la fiabilidad está relacionada con la confianza en el periodista (Pearson=0.42; $p=0.00$ ).

En cuanto a los criterios de la credibilidad percibida del periodismo en general, los medios in- formativos y el aporte del autor o periodista a los mismos están relacionados (Pearson $=0.32$; $p=0.00$ ); así como el medio y el contenido de las notas periodísticas que publica (Pearson $=0.29$; $p=0.00$ ). No obstante, el aporte del periodista al medio en que publica y el contenido que se publica en el mismo no están relacionados (Pearson=0.07; $p=0.35$ ), lo que resulta discordante ya que, en parte, el aporte de los periodistas a la credibilidad de los medios informativos se basa en el contenido que ellos producen y los medios publican.

Finalmente, también se halló una baja correlación entre la credibilidad y la dependencia al Internet (Pearson=0.19; $p=0.01$ ).

\section{Discusión}

Los resultados señalan que los consumidores de información periodística en Internet juzgan la credibilidad de la información noticiosa a partir de sus propias experiencias con los medios, así como en sus propias percepciones y opiniones sobre el medio, lo que resulta contrario con el proceso de influencia social descrito por Cialdini y Mortensen (2007), es decir, que estos consumidores no toman en cuenta las opinión de los demás, por lo que no se presenta influencia por conformidad en este caso. Sin embargo, también se observó que el nombre del medio informativo más usado por los consumidores fue de medios que son tradicionalmente leídos en Colombia. Entonces, estos medios son creíbles tanto por sus condiciones particulares que los diferencian, como por la experticia y confiabilidad en los autores que allí publican, lo que resulta consistente y extiende al ámbito del internet lo propuesto por Hovland y otros (1953) y los fundamentos propuestos de la credibilidad: la atribuida, la satisfacción de necesidades y el uso de la información por parte de los consumidores de noticias online.

Según los tipos de credibilidad señalados por Fogg (2003), los consumidores de información, participantes en este estudio, basarían su credibilidad en la experiencia, ya que fue reportada como lo más importante para juzgarla. 
Los resultados respecto a la credibilidad en la Internet y la dependencia de este, por parte del consumidor discrepan de lo hallado por Cassidy (2007), con alto grado de dependencia al Internet se encontraron puntuaciones más bajas en cuanto al nivel de credibilidad de este medio. No obstante, se hallaron resultados similares a los encontrados por Busy (2003), donde los más jóvenes suelen juzgar como creíble en primer lugar al internet. De todas formas, hay que recordar que los más jóvenes tienen actualmente más cercanía a estos medios y son más fácilmente influenciables en general, lo que también resulta consistente con lo descubierto por Kiousis (2006) en términos de la relación entre el uso de multimedia en el periodismo virtual y la credibilidad percibida.

Los resultados son consistentes con lo encontrado por Gaziano y McGrath (1986), Moya (1999), O'Keefe (2002) y Pornpitakpian (2004) en relación con los vínculos entre la competencia, la experticia, la confianza, la fiabilidad y el sesgo del autor y la credibilidad percibida. Igualmente, la dependencia del Internet, la confianza en los mensajes y en su contenido se hallan relacionadas con la credibilidad percibida, como lo reportó Cassidy (2007).

En cuanto a las variables sesgo y el uso o no de citas, estudiadas experimentalmente por Sundar (1998), se encontró que, para la muestra obtenida en este estudio, es muy importante incluir citas o fuentes al menos conocidas, como también lo han reportado Hovland y otros (1953), Lui (1989) y Tormala y otros (2007). Además de incluir un punto de vista imparcial en el contenido del mensaje.

Con los datos obtenidos se evidencia que los resultados resultan consistentes con otras investigaciones. Particularmente, las variables que son tomadas en cuenta al juzgar la credibilidad son, la reputación del autor y del medio, tal como se encontró en Cialdini \& Mortensen (2007). No obstante, estos mismos autores hallaron, por otro lado, que el autor/periodista y el contenido que publica el medio están relacionados, situación contraria a la encontrada en el presente estudio. Lo anterior sugiere la necesidad de profundizar en este tema, en futuros proyectos de investigación, explorando, por ejemplo, variables de tipo cultural u otras relacionadas con la calidad de los medios informativos online que pudiesen explicar estas diferencias, ya que resulta por lo menos lógico que el contenido del mensaje que genera un periodista aportaría a su credibilidad y que no se encontró con los datos recaudados.

En este sentido, el modelo factorial de Hovland, Janis y Kelley (1953) podría ser una alternativa para analizar esta posible inconsistencia, además, buscar una explicación alternativa a correlaciones inferiores a 0.5 halladas entre los diferentes factores que determinan la credibilidad del autor/ periodista y la credibilidad percibida general, al igual que entre esta y la dependencia del internet. En este sentido, podría haber factores vinculados a los propósitos de uso informativo del Internet que estuviesen afectando la dependencia o no de este popular medio.

Finalmente, con métodos experimentales o estudios longitudinales, sería posible explorar con más detalle los efectos de la credibilidad, tal y como lo proponen Wathen y Burkell (2002), en relación con el uso que se hace de la información periodística en general y particularmente en los efectos psicológicos de esta sobre la toma de decisiones, y el cambio en las actitudes y en el comportamiento de los consumidores virtuales de noticias. En conclusión, son muchas las variables que, en conjunto, las ciencias del comportamiento y de la comunicación pueden estudiar a fin de proponer modelos que mejoren la calidad informativa del periodismo en general $y$, en general, de la información que se produce para el Internet.

\section{Referencias}

Blackwell, R., Miniard, P. \& Engel, J. (2002). Comportamiento del Consumidor. México: Thomson.

Busy, E. (2003). Media credibility reconsidered: synergy effects between on-air and online news. Journalism \& Mass Communication Quarterly, 80(2), 247-264. 
Cassidy, W. (2007). Online News Credibility: An Examination of the Perceptions of Newspaper Journalists. Journal of Computer-Mediated Communication, 12, 144-164.

Cialdini, R. \& Mortensen, C. (2007). 21st Century Psychology: A Reference Handbook. SAGE Publications. Recuperado el 17 de septiembre de 2009 de http://sage-ereference.com/ psychology/Article_n65.html.

Flanagin, A. \& Metzger, M. (2008). The credibility of volunteered geographic information. GeoJournal, 72, 137-148. DOI: 10.1007/s10708008-9188-y.

Fogg, B. (2003). Prominence-Interpretation theory: explaining how people assess credibility online. Conference on Human Factors in Computing Systems, 722-723. Ft. Lauderdale: Florida (USA).

Galegher, J., Sproull, L. \& Kiesler, S. (1998). Legitimacy, authority, and community in electronic support groups. Written Communication, 1-31.

Gaziano, C. \& McGrath, K. (1986). Measuring the concept of credibility. Journalism Quarterly, 63(3), 451-462.

Greer, J. (2003). Evaluating the credibility of online information: a test of source and advertising influence. Mass Communication and Society, 6(1), 11-28.

Hernández, S., Fernández, C. \& Baptista, P. (2006). Metodología de la investigación. Bogotá: McGraw-Hill.

Hovland, C. I., Janis, I. L. \& Kelley, H. H. (1953). Communication and persuasion. New Haven, CT: Yale University Press.

Johnson T. J. \& Kaye, B. K. (2000). Using is believing: The influence of reliance on the credibility of online political information among politically interested Internet users. Journalism \& Mass Communication Quarterly, 77, 865-879.
Kiousis, S. (2006). Exploring the impact of modality on perceptions of credibility for online news stories. Journalism Studies, 7, 348-358. DOI: 10.1080/14616700500533668

Loudon, D. \& Della Bitta, A. (1995). Comportamiento del consumidor. México: McGraw-Hill.

Lui, L. (1989). Comunicator credibility: Trustworthiness defeats expertness. Social Behavior and Personality, 17, 219-221.

McCombs, M. E. \& Shaw, D. L. (1972). The agendasetting function of mass media. Public Opinion Quarterly, 36(2), 176-187.

Monzón, C. (1996). Opinión pública, comunicación y política. La formación del espacio público. Madrid: Ed. Tecnos.

Moya, M. (1999). Persuasión y cambio de actitudes. En F. Morales y Moya (Coord.). Psicología Social. Madrid: McGraw-Hill.

Myers, D. (2005). Psicología Social. México: McGraw-Hill.

Nozato, Y. (2002). Credibility of online newspapers. Documento presentado en la Convención Anual de la Association for Education in Journalism and Mass Communication. Washington, D.C., august, 2002.

O'Keefe, D. (2002). Persuasión: Theory and Research. Thousand Oaks, CA: Sage Publications.

Pardo, J. (1989). La banalidad. Barcelona: Editorial Anagrama.

Pornpitakpan, C. (2004). The persuasiveness of source credibility: A critical review of five decades' evidence. Journal of Applied Social Psychology, 34(2), 249-281.

Rieh, S. \& Danielson, D. (2007). Credibility: A multidisciplinary framework. Annual Review of Information Science and Technology, 41, 307-364. 
Robinson, S. (2008). A Columnist's call to action: audience perceptions of credibility and authority online vs. in print. Ninth International Symposium on Online Journalism, April 3-4. Recuperado el 24 de septiembre de 2010 de: http://online.journalism.utexas.edu/2008/ papers/Robinson.pdf

Santos Calderón, E. (1989). El periodismo en Colombia, 1886-1986. En A. Tiraldo Mejía (Comp.). Nueva Historia de Colombia. Tomo VI. Bogotá: Planeta.

Schweiger, W. (2000). Media credibility - experience or image?: A survey on the credibility of the World Wide Web in Germany in comparison to other media. European Journal of Communication, 15, 37-59.

Sternthal, B., Dholakia, R. \& Leavitt, C. (1978). The persuasive effect of source credibility: tests of cognitive response. Journal of Consumer Research, 4, 252-260.

Stavrositu, C. \& Sundar, S. (2008). If internet credibility is so iffy, why the heavy use? the relationship between medium use and credibili- ty. Cyberpsychology \& Behavior, 11(1), 65-70. DOI: 10.1089/cpb.2007.9933

Swan, C. (2004). Web design's effect on perceived credibility of online news stories. Master of Arts Thesis in Mass Communication, University of Florida.

Sundar, S. (1998). Effect or source attribution on perception of on line news stories. Journalism \& Mass Communication Quarterly, 75, 55-68.

Tormala, Z., Briñol, P. \& Petty, R. (2007). Multiple roles for source credibility under high elaboration: it's all in the timing. Social Cognition, 25, 536-552.

Thomson, J. (1998). Los media y la modernidad. Una teoría de los medios de comunicación. Barcelona: Paidós.

Wathen, N. \& Burkell, J. (2002). Believe it or not, factors influencing credibility on the Web. Journal of the American Society for Information Science and Technology, 53(2), 134-144. DOI: 10.1002/asi.10016. 